\title{
Correction to: A Systematic Literature Review of Information Sources for Threat Modeling in the Power Systems Domain
}

\author{
Engla Ling (10, Robert Lagerström (i), and Mathias Ekstedt (1)
}

\begin{abstract}
Correction to:
Chapter "A Systematic Literature Review of Information

Sources for Threat Modeling in the Power Systems Domain"

in: A. Rashid and P. Popov (Eds.): Critical Information

Infrastructures Security, LNCS 12332,

https://doi.org/10.1007/978-3-030-58295-1_4
\end{abstract}

Chapter 4, "A Systematic Literature Review of Information Sources for Threat Modeling in the Power Systems Domain" was previously published non-open access. It has now been changed to open access under a CC BY 4.0 license and the copyright holder updated to 'The Author(s)'. The book has also been updated with this change. 